\title{
Diarrhea Prevention Practice and Associated Factors among Caregivers of Under-Five Children in Enemay District, Northwest Ethiopia
}

\author{
Melese Dubie Agegnehu, ${ }^{1}$ Liknaw Bewket Zeleke $\mathbb{D}^{1},{ }^{2}$ Yitayal Ayalew Goshu ${ }^{D},{ }^{3}$ \\ Yonas Lamore Ortibo, ${ }^{2}$ and Yohannes Mehretie Adinew (iD ${ }^{4}$ \\ ${ }^{1}$ World Vision, Addis Ababa, Ethiopia \\ ${ }^{2}$ College of Health Sciences, Debre Markos University, Debre Markos, Ethiopia \\ ${ }^{3}$ College of Health Sciences and Medicine, Debre Tabor University, Debre Tabor, Ethiopia \\ ${ }^{4}$ College of Health Sciences and Medicine, Wolaita Sodo University, Ethiopia
}

Correspondence should be addressed to Liknaw Bewket Zeleke; bliknaw08@gmail.com

Received 24 October 2018; Revised 2 February 2019; Accepted 11 February 2019; Published 12 May 2019

Academic Editor: Pauline E. Jolly

Copyright (C) 2019 Melese Dubie Agegnehu et al. This is an open access article distributed under the Creative Commons Attribution License, which permits unrestricted use, distribution, and reproduction in any medium, provided the original work is properly cited.

\begin{abstract}
Background. Diarrhea is the leading cause of mortality among infants and children younger than 5 years of age in both underdeveloped and developing countries. Factors determining the occurrence of diarrhea in children are complex, and the relative contribution of each factor varies as a function of interaction between socioeconomic, environmental, and behavioral variables. Objectives. To assess diarrhea prevention practice and associated factors of diarrheal disease among caregivers who have underfive children in Enemay district, Ethiopia, 2018. Methods. Community-based cross-sectional study was done from June 1-30, 2018, among 398 caregivers who have under-five children, in the Enemay district that were selected by using the simple random sampling technique. A structured and pretested data collection tool was used to collect the data. Data were entered using EPI DATA version 4.2, and analysis was done using SPSS version 20 statistical package to be cleaned and analyzed. Descriptive analysis was done to describe study participants, and logistic regression (bivariable and multivariable) analysis was done to identify factors that have association with the dependent variable. The $P$ value was less than 0.05 . Results. A total of 398 with a response rate of $97 \%$ under-five caregivers were participated in this study. Nearly, half (48.7\%) of the participants were in the age group 25-34. The study revealed that good practice of diarrhea prevention was $52.8 \%$. This study was also identified that occupation (AOR: 3.922 , 95\% CI: 1.593, 9.657), family size (AOR: 0.088, 95\% CI: 0.009, 0.916), and understanding on diarrhea (AOR: 0.237, 95\% CI: 0.091, 0.613 ) were associated factors of diarrhea prevention practice of under-five children caregivers. Conclusion. This finding showed that diarrhea prevention practice among under-five children caregivers was low and prevention practice was significantly associated with caregivers' awareness on frequency of diarrhea in a day, occupation, and family size in a house.
\end{abstract}

\section{Background}

Diarrhea is the passage of loose or watery stools occurring three or more times in a 24-hour period which means an increased frequency or decreased consistency of bowel movements, and it affects people of all ages [1]. It is usually a symptom of an infection in the intestinal tract, which can be caused by a variety of bacterial, viral, and parasitic organisms [2].
Diarrhea is the second leading cause of child morbidity and mortality, especially in the developing countries. Globally, it is estimated that there are 2.5 billion episodes and 1.5 million deaths annually in children under five years [3].

Diarrheal diseases are major causes of malnutrition, delayed physical development, and early childhood mortality in developing countries and poor communities, and the major cause of death in children with diarrhea is loss of water and essential minerals [4]. 
In sub-Saharan Africa, primary caregivers display poor perception about the signs of dehydration, dysentery, and management of diarrhea [5].

The incidence of illnesses contributing to avoidable deaths diarrhea is higher in Ethiopia compared to other sub-Saharan African countries partly due to different factors [6]. In Ethiopia, diarrheal disease is a major public health problem, and it is one of the top 15 countries in which nearly threefourths of child deaths occur due to diarrhea [4]. In Ethiopia, morbidity reports and community-based studies indicate that diarrheal diseases are a major public health problem that causes excess morbidity and mortality among children [7]. The prevalence in Enemay woreda is $18.6 \%$ which indicates diarrhea is still the burden in the study area [8].

Various preventive techniques were reported in the literatures including hygiene and sanitation, diet, medications, and supplements which are generally classified as health care, breastfeeding, immunization, supplemental zinc, and probiotics [9]. Treatment and prevention of diarrhea can be done at home by primary caregivers, and their role is vital in health promotion, disease prevention, and patient care [4].

Prevention practice of caregivers is important and can prevent diarrhea-related child morbidity and mortality. Therefore, the study aimed at identifying the gaps on under-five children diarrhea prevention practice and associated factors in the study area so as to forward recommendations for underfive caregivers, local health-care providers, and other stakeholders to reduce diarrhea-related morbidity and mortality. The community at large in the study area can be benefited from improved under-five diarrhea prevention practice.

\section{Methods}

2.1. Study Design. Community-based cross-sectional study was conducted.

2.2. Study Area and Period. The study was conducted in Enemay district, East Gojjam zone, Amhara regional state, northwest Ethiopia, from June 1-30, 2018. The Enemay district is located $370 \mathrm{~km}$, northwest of Addis Ababa, the capital city of Ethiopia, and $220 \mathrm{~km}$ southwest of Bahir Dar city, the capital of the Amhara National Regional State, respectively. The total population in the district is 198241, of which 26404 are under-five children. The district has one district hospital, 7 health centers, and 34 health postsites. All these health facilities involve in diarrhea prevention and control. Access to safe water supply in the district is 62\% [10].

2.3. Source Population. All caregivers of under-five children in the Enemay district were the source populations, and the study population was all caregivers of under-five children in the selected kebeles.

2.4. Sample Size Determination. Single population proportion formula was employed using population proportion $41.3 \%[5]$.
With confidence level $95 \%$ and margin of error $5 \%$, $n=\left(Z_{\alpha} / 2\right)^{2} p(1-P) / d^{2}$, where $n$ is the sample size, $P$ is the population proportion of diarrhea prevalence, $d$ is the margin of error (0.05), and $\alpha$ is $5 \%$.

So using the above formula, the sample size is $n=z^{2} p\left((1-p) / d^{2}\right)$

$=\left((1.96)^{2} \times 0.413\right)\left((1-0.413) /(0.05)^{2}\right)=373$.

The final sample size with $10 \%$ nonresponse rate is 410 .

2.5. Sampling Technique. The study was conducted using simple random sampling. Six kebeles were selected by lottery method from all 29 kebeles in the Enemay district. Finally, the required number of under-five caregivers was selected by using the simple random sampling technique from the list obtained from health extension workers in selected kebeles.

2.6. Data Collection Procedure. Data were collected by interviewer-administered interview and observation using semistructured questionnaire. The questionnaire was prepared in English initially by reviewing the literatures and then translated in to the Amharic version which later on translated back to the English version to check its consistency and comparability of the finding. Six health extension data collectors and one BSc nursing supervisor were recruited to data collection in the Enemay district. Training was given for data collectors and supervisor on objectives of the study, method of collecting the needed information through interviewing and observation, how to fill the information on the questionnaire, and the ethical aspect in approaching the participants which should be in a polite and respectful manner. The supervisor had been monitoring the data collection process, and the investigators were available to respond the concerns raised from the data collector and the supervisor. The older children were considered when two or more under-five children were found in the house.

\subsection{Operational Definition}

2.7.1. Good Diarrhea Prevention Practice. Participants who scored above the mean value of practice question [11].

2.7.2. Clean Latrine. No fecal matter in and around the pit latrine, properly swept.

2.7.3. Hand Washing at Critical Time. It includes washing hand after using a toilet, after cleaning a child, after any cleaning activity, before preparing food, before meal, and before breastfeeding.

2.7.4. Caregiver. A caregiver is an individual who could be a parent, foster parent, or head of the household who attends to the needs of a child or primary caregiver [12].

2.8. Data Quality Assurance. The questionnaire was adapted from literatures and modified into local context. Training was given for data collectors and supervisor. Pretesting of the 
questionnaire was made on $5 \%$ of the sample size in adjacent kebele prior to the actual data collection. The data collection process was strictly followed day to day by the supervisor, and data were checked for its completeness by the principal investigator. During analysis, not eligible variables for the analysis method were excluded by checking the chi-square test, and the model fitness test was also computed.

2.9. Data Analysis Technique. Data were coded and entered into EPI DATA version 4.2 and exported to SPSS version 20 for statistical analysis. Descriptive analysis was done to describe study participants in terms sociodemographic characteristics. Bivariate logistic regression analysis was done to determine the association between each independent and dependent variable. All factors that were associated with the dependent variable in bivariate analysis with a $P$ value of 0.20 or less were included in the beginning of multivariable analysis to identify the associated variables. A $P$ value $<0.05$ and corresponding $95 \%$ CI of odds ratio were considered to declare a result as statistically significant in this study in multivariable regression. The odds ratio together with $95 \%$ confidence intervals was used to interpret the strength and direction of association.

2.10. Ethical Consideration. Ethical clearance was obtained from Ethical Review Committee, College of Health Sciences, Debre Markos University, and letter of permission was obtained from the Enemay district health office. The purpose of the study was explained to respondents, and verbal informed consent was obtained from participants. Confidentiality of information was maintained by keeping anonymous personal identifiers. Children who were found with active diarrheal disease during house-to-house visit for data collection were linked to health facilities for treatment.

\section{Results}

3.1. Sociodemographic Characteristics. A total of 398 underfive children caregivers participated in the study, making the response rate of the study as $97 \%$. Among the respondents, nearly half $(48.7 \%)$ were between $25-34$ years with the mean age of 33.2. Around two-thirds of the participants (66.1\%) and their husband (65.1\%) had no formal education. Concerning occupation of the participants, majority $(87.2 \%)$ participants were housewives. Regarding family size, 228 (57.3\%) participants had less than four family members per household and 392 (98.5\%) of caregivers had less than two under-five children. (Table 1)

3.2. Knowledge on Diarrhea Prevention Practice. Out of 398 caregivers, $62.6 \%$ had information on diarrhea and nearly one-third $(34.4 \%)$ of the participants recognized diarrhea as passage of watery stool once in a day. More than half of the caregivers considered latrine utilization (54.8\%) and hand washing (51.5\%) as prevention methods for diarrhea. In addition, 261 (65.6\%) of caregivers respond watery diarrhea as sign and symptoms of diarrhea. Questions were also asked for caregivers about causes of diarrhea, and $70.1 \%$ respond contaminated food. Concerning treatment seeking behavior of the participants, $37(31.9 \%)$ participants stay at home without treatment when their child had diarrhea (Table 2).

3.3. Attitude towards Diarrhea Prevention Practice. About $252(60.6 \%)$ participants disagreed on the likelihood of their child to get diarrhea in the next month whereas one hundred fifty eight $(37.7 \%)$ of caregivers disagreed that diarrhea is normal in children. About 166 (39.2\%) of caregivers agreed that diarrhea is a preventable disease, and 110 (27.6\%) of caregivers disagreed that diarrhea is a preventable disease. Among the total participants, nearly half (50.5\%) agreed that diarrhea is a communicable disease and $41.5 \%$ of caregivers strongly agreed that diarrhea can be caused by open defecation.

3.4. Environmental Factors. From the total study participants, nearly two-thirds $(68.8 \%)$ had latrine in their premise from which almost half (50.4\%) were unimproved. Concerning hand washing facility, 147 (36.9\%) participants had hand washing facility in their premise during study period. Nearly one out of five participants $(80.2 \%)$ of caregivers obtain drinking water from well-protected source and around half (55\%) of caregivers spend longer than 30 minutes (round trip) to obtain their drinking water.

\subsection{Under-Five Caregivers' Diarrhea Prevention Practice.} Two hundred forty nine $(62.6 \%)$ of the participants treat their drinking water source using chlorine, and 233 (58.4\%) of participants use latrine for defecation. From the total study participants, under-five caregivers asked about hand washing times, $272(68.3 \%)$ respond that they wash their hands after toilet visit and only 151 (37.9\%) wash their hands before child feeding. One hundred sixty four (41.2\%) caregivers wash their hands using only water. Only $27 \%$ latrines were clean during data collection. About half (50.5\%) of caregivers feed their child exclusively for six months (Table 3).

As shown by the figure below, the overall diarrhea prevention practice among caregivers' of under-five children in the Enemay district, Amhara regional state, northwest Ethiopia, was $52.8 \%$.

3.6. Factors Associated with Diarrhea Prevention Practice. Factors associated with diarrhea prevention were identified by computing bivariate and multivariate analyses. Occupation, knowledge on immunization to prevent diarrhea, family size, information on diarrhea, and fluid importance during diarrhea sickness and awareness of diarrhea frequency showed association in bivariate analysis whereas in multivariable analysis, occupation of caregivers, family size, and awareness on diarrhea frequency showed significant association.

Under-five diarrhea prevention practice among housewives was 3.9 times more likely (AOR: 3.922, 95\% CI: 1.593, 9.656) than merchants and others. 
TABle 1: Distribution of sociodemographic characteristics of study caregivers' in Enemay district, northwest Ethiopia, 2018.

\begin{tabular}{|c|c|c|c|}
\hline Variable name & Category & Frequency & Percent \\
\hline \multirow{3}{*}{ Age } & $15-24$ & 50 & 12.6 \\
\hline & $25-34$ & 194 & 48.7 \\
\hline & $>35$ & 154 & 38.7 \\
\hline \multirow{2}{*}{ Sex } & Male & 8 & 2.0 \\
\hline & Female & 390 & 98.0 \\
\hline \multirow{2}{*}{ Religion } & Orthodox & 294 & 73.9 \\
\hline & Muslim & 103 & 26.1 \\
\hline \multirow{4}{*}{ Occupation } & Housewife & 347 & 87.2 \\
\hline & Student & 7 & 1.8 \\
\hline & Employed & 11 & 2.8 \\
\hline & Merchant & 33 & 8.3 \\
\hline \multirow{3}{*}{ Education } & No formal education & 263 & 66.1 \\
\hline & Primary $(1-8)$ & 111 & 27.9 \\
\hline & Secondary (9-12) and above & 24 & 6.0 \\
\hline \multirow{3}{*}{ Husband education } & No formal education & 259 & 65.1 \\
\hline & Primary $(1-8)$ & 119 & 29.9 \\
\hline & Secondary (9-12) and above & 20 & 5.0 \\
\hline \multirow{2}{*}{ Family size } & $<4$ & 228 & 57.3 \\
\hline & $5-8$ & 170 & 42.7 \\
\hline \multirow{2}{*}{ No. of $5<$ children } & $1-2$ & 392 & 98.5 \\
\hline & 3-4 & 6 & 1.5 \\
\hline \multirow{3}{*}{ Relation to child } & Mother & 301 & 75.6 \\
\hline & Sister & 89 & 22.4 \\
\hline & Father & 8 & 2 \\
\hline \multirow{4}{*}{ Average monthly income } & $1401-2350$ & 215 & 54 \\
\hline & $2351-5000$ & 131 & 33 \\
\hline & $>5000$ & 5 & 1.2 \\
\hline & No income & 47 & 11.8 \\
\hline \multirow{3}{*}{ Marital status } & Single & 11 & 2.8 \\
\hline & Married & 382 & 95.9 \\
\hline & Divorced & 5 & 1.3 \\
\hline
\end{tabular}

Diarrhea prevention practice in caregivers with family size 5-8 was $91.2 \%$ less likely (AOR: 0.088 , 95\% CI: 0.009 , 0.916) than those that have family size less four.

Caregivers who perceived diarrhea as passage of watery stool two times in a day were $76.3 \%$ less likely $(0.091,0.613)$ to practice diarrhea prevention in under-five children than who perceived three times in a day (Table 4).

\section{Discussion}

From the total participants of the study, 58.4\% were utilizing latrine properly. The findings are in line with the study in Gulomekada District, north Ethiopia, where rate of latrine utilization was about $57.3 \%$ [13]. This finding is higher than a study finding reported from Farta Woreda, northwest Ethiopia, where latrine utilization habit was $29.2 \%$, and Asmara, Eritrea, which indicated $72.2 \%$ of participants are defecating in open field $[6,14]$. The difference might be attributed to the difference in the sociodemographic characteristics and basic environmental infrastructure of study households, behaviors of the participants, and awareness of the community.

The present study revealed that $62.6 \%$ of caregivers use chlorine-treated drinking water. This is higher than a study finding in Farta Woreda, northwest Ethiopia, where only $4.9 \%$ of the participants treat their drinking water and lower than a finding in Dejene woreda, Ethiopia, where $81 \%$ add bleach to treat drinking water $[6,15]$. The difference might be due to sociodemographic factors, accessibility of supplies, and difference in study period.

In this study, $41.2 \%$ of caregivers wash their hands using only water which may not be effective in removing of disease-causing bacteria, and it could be source of contamination during washing their hand which is another risk for diarrhea transmission. The reported practice of hand washing is slightly higher than the observed availability of hand washing facility. The disparity may be resulted from utilization of traditional methods of hand washing without preparing or availing hand washing facilities. In the other case, hand washing with soap was lower (26.4\%) than with plain water. The discrepancy might be due to unaffordability for frequent buying of soap. Similar finding was reported by a study carried out in India that demonstrated $41 \%$ hand washing is with using water only [16]. This finding is less than the study conducted in Farta, Ethiopia, where $56.3 \%$ of the respondents used only water to wash their hands [6]. The difference might be due to sociodemographic and economic factors. 
TABLE 2: Knowledge distribution of caregivers about under-five diarrhea prevention in Enemay district, northwest Ethiopia, 2018.

\begin{tabular}{|c|c|c|c|}
\hline Variable name & Category & Frequency & Percent \\
\hline \multirow{2}{*}{ Information on diarrhea } & Yes & 249 & 62.6 \\
\hline & No & 149 & 37.4 \\
\hline \multirow{4}{*}{ Awareness on frequency of diarrhea } & Watery diarrhea once in a day & 137 & 34.4 \\
\hline & Watery diarrhea twice in day & 95 & 23.9 \\
\hline & Watery diarrhea three times in a day & 78 & 19.6 \\
\hline & Watery diarrhea four times in a day & 88 & 22.1 \\
\hline \multirow{6}{*}{ Sign and symptom of diarrhea } & Vomiting & 118 & 29.6 \\
\hline & Fever & 130 & 32.7 \\
\hline & Dehydration & 163 & 40.9 \\
\hline & Appetite loss & 176 & 44.2 \\
\hline & Weakness & 144 & 36.2 \\
\hline & Watery diarrhea & 261 & 65.6 \\
\hline \multirow{6}{*}{ Cause of diarrhea } & Insects & 99 & 24.9 \\
\hline & Contaminated water & 262 & 65.8 \\
\hline & Contaminated food & 279 & 70.1 \\
\hline & Bad sprit & 76 & 19.1 \\
\hline & Poor sanitation & 197 & 49.5 \\
\hline & Bad smell & 64 & 16.1 \\
\hline \multirow{2}{*}{ Type of diarrhea you know } & Bloody & 116 & 29.1 \\
\hline & Watery with no blood & 282 & 70.9 \\
\hline \multirow{4}{*}{ Diarrhea treatment } & No treatment & 37 & 31.9 \\
\hline & Homemade ORS & 33 & 28.4 \\
\hline & Took to health facility & 36 & 31.1 \\
\hline & Visit traditional healer and others & 10 & 8.6 \\
\hline \multirow{5}{*}{ Prevention of diarrhea } & Breastfeeding & 173 & 43.5 \\
\hline & Eat safe food & 202 & 50.8 \\
\hline & Use latrine & 218 & 54.8 \\
\hline & Immunization & 182 & 45.7 \\
\hline & Hand washing & 205 & 51.5 \\
\hline
\end{tabular}

TABLE 3: Under-five caregivers' diarrhea prevention practice in Enemay district, northwest Ethiopia, 2018.

\begin{tabular}{|c|c|c|c|}
\hline Variable name & Category & Frequency & Percent \\
\hline \multirow{5}{*}{ Water treatment } & Boiling & 95 & 23.9 \\
\hline & Chlorine & 249 & 62.6 \\
\hline & Filter with close & 14 & 3.5 \\
\hline & Nothing & 40 & 10.1 \\
\hline & After toilet visit & 272 & 68.3 \\
\hline \multirow{5}{*}{ Hand washing } & Before food preparation & 199 & 50 \\
\hline & Before meal & 259 & 65.1 \\
\hline & After any cleaning & 212 & 50.3 \\
\hline & Before feeding/breastfeeding & 151 & 37.9 \\
\hline & After child cleaning & 139 & 9.8 \\
\hline \multirow{3}{*}{ Hand hygiene materials } & Water only & 164 & 41.2 \\
\hline & Water with ash & 129 & 32.4 \\
\hline & Water with soap & 105 & 26.4 \\
\hline \multirow{2}{*}{ Was the latrine clean? } & Yes & 200 & 73.0 \\
\hline & No & 74 & 27.0 \\
\hline \multirow{3}{*}{ Exclusive breastfeeding } & $>6$ month & 127 & 31.9 \\
\hline & 6 month & 251 & 63.1 \\
\hline & $<6$ month & 20 & 5.0 \\
\hline \multirow{2}{*}{ Immunization status } & Completed & 354 & 88.9 \\
\hline & Not completed & 44 & 11.1 \\
\hline \multirow{2}{*}{ Initiation of first breast milk } & Within 1 hour & 282 & 70.8 \\
\hline & After 1 hour & 116 & 29.2 \\
\hline
\end{tabular}


TABLE 4: Factors associated with under-five diarrhea prevention practice among caregivers, Enemay district, Ethiopia, 2018.

\begin{tabular}{lccccc}
\hline \multirow{2}{*}{ Variables } & \multicolumn{2}{c}{$\begin{array}{c}\text { Prevention } \\
\text { practice }\end{array}$} & COR (95\% CI) & AOR (95\% CI) \\
& & Poor & Good & & \\
\hline Immunization & Yes & 91 & 91 & $1.23(0.49,0.91)$ & $1.17(0.71,1.94)$ \\
Prevent diarrhea & No & 697 & 119 & 1 & 1 \\
Occupation & House wife & 168 & 179 & $1.27(1.01,1.59)$ & $3.92(1.59,9.66)^{*}$ \\
& Merchants and others & 20 & 31 & 1 & 1 \\
Family size & $\geq 5$ & 61 & 109 & $0.45(1.33,2.89)$ & $0.09(0.01,0.92)^{*}$ \\
Information on diarrhea & $\leq 4$ & 127 & 101 & 1 & 1 \\
& Yes & 127 & 122 & $0.67(0.44,0.99)$ & $0.1 .503(0.86,2.64)$ \\
Frequency of diarrhea & No & 61 & 88 & 1 & 1 \\
& Once/twice/day & 96 & 136 & $0.64(1.61,7.67)$ & $0.24(0.09,0.61)^{*}$ \\
Fluid during diarrhea & $>/=$ times/day & 87 & 79 & 1 & 1 \\
& Yes & 111 & 114 & $1.71(1.15,2.55)$ & 1 \\
\hline
\end{tabular}

*Significantly associated; COR, crude odds ratio; AOR, adjusted odds ratio.

In this study, caregivers were asked about hand washing at critical times, and from the total participants, $65.1 \%$ wash their hands before meal, 50\% wash their hands before food preparation, $37.9 \%$ wash their hands before feeding children, $9.8 \%$ wash their hands after cleaning children, $50.3 \%$ wash their hands after any cleaning activity, and $68.3 \%$ wash their hands after visiting toilet.

The present study revealed that about $73 \%$ latrines were clean. This is line with the study conducted in Aneded District, northwest Ethiopia, where about $66.7 \%$ of latrines were clean [17]. This might be due to similar sociodemographic status of the community.

The findings of this study revealed that $63.1 \%$ of caregivers practiced exclusive breastfeeding for six months. This finding is different from that of the study conducted in Jigjiga District, Somali Region, eastern Ethiopia in which $84.4 \%$ of the children were not exclusively breastfed in the first 6 months of their life and in 33.6\% in Ibadan, Nigeria $[7,18]$. The difference might be due to sociodemographic factors and difference in study design.

This study also found that about $88.9 \%$ of children completed their course of vaccination. This study is different from a study conducted in Dejen district, northwest Ethiopia, where only $48.6 \%$ were fully vaccinated [15]. The difference might be due difference level of awareness, accessibility of health facility, and supplies.

In this finding, about $52.8 \%$ of caregivers scored above the mean value of practice-related questions that had good diarrhea prevention practice. This is lower than from a study conducted in Indonesia where $68.3 \%$ of caregivers had good behaviors of preventing diarrhea [19]. The difference might be due to level of awareness, educational status, sociodemographic factors, and others. The finding is higher than findings of studies conducted in Fagita Lekoma district (37.6\%) [19], South Sudan (42.2\%) [20], and Finote Selam town $(45.9 \%)$ [6].

In this study, housewife caregivers were 3.9 times more likely to practice diarrhea prevention in under-five children than merchants and others (AOR: 3.922, 95\% CI: 1.593, 9.657). This is supported by the study done in Iran, where occupation was significantly associated with diarrhea prevention practice [21]. The reason may be that housewives could have the opportunity to get information from different sources as they have sufficient time to gain information from different sources and to practice it. This finding is different from the study conducted in Fagita Lekoma district, Ethiopia, where occupation was not significantly associated with diarrhea prevention [22]. This difference might be due to level of education, sociodemographic status, and sociocultural characteristics.

In this study, caregivers who had 5 or more family size were $91.2 \%$ less likely to practice diarrhea prevention in under-five children than those who had less than four family size. This finding is in agreement with a study finding from Gojam Hullet Ejju Ense woreda, Ethiopia, where greater family size was associated with diarrhea morbidity [23]. But contradicts from a study finding in Derashe District, Southern Ethiopia, where family size was not significantly associated with diarrhea disease [20]. The difference might be socioeconomic status, environmental factors, education level, living condition, and difference in time of study.

Caregivers who respond frequency of diarrhea two times were $76.3 \%$ less likely to practice than who answered three times in a day. This is the finding supported by the study conducted in Ethiopia where mothers who had no understanding about diarrhea were by $80.3 \%$ less likely to have good practice compared with their counterparts [22]. This may be due to the fact that mothers who had information about diarrhea have a good opportunity to good prevention practice. This study is different from a study conducted in Nigeria, where $93 \%$ respondents were aware of diarrhea and had understanding on it [24]. This might be due to caregivers' lack of prior experience, educational status, and source of information.

The key strengths of the study were the design which is community based and involvement of adequate sample size. The basic limitations of the study were difficulty to know the cause and effect, at the same time resulted from its nature of cross-sectional study and under or over reported depending on the recent health-care workers activity because they 
might think of that children could receive medical attention through the study.

\section{Conclusion}

The result of this study showed that diarrhea prevention practice among under-five children caregivers was low, and the practice of diarrhea prevention practice was significantly associated with information on frequency of diarrhea, occupation, and family size in a house. Stakeholders have to focus on efforts to control diarrheal diseases and on increasing the level of knowledge and behavior of diarrhea prevention practice through increasing family planning and behavioral change.

\section{Data Availability}

The data used to support the findings of this study are available from the corresponding author upon request.

\section{Ethical Approval}

Debre Markos University Research Ethics Review Committee reviewed the ethical acceptability of the research.

\section{Consent}

Informed consent was obtained from each participant during data collection.

\section{Conflicts of Interest}

The authors declare that they have no conflicts of interest.

\section{Authors' Contributions}

MDA, LBZ, and YMA wrote the proposal, participated in data collection, analyzed the data, and drafted the paper. LBZ, YAG, and YL drafted the manuscript. All authors read and approved the final manuscript.

\section{Acknowledgments}

We are very grateful to Debre Markos University for the financial support to this study and all study participants for their commitment in responding to our questionnaire. The study was funded by Debre Markos University. The university supported the study by ensuring the ethical acceptability and financially covered the costs for data collector training and data collectors' perdium during data collection.

\section{References}

[1] O. Y. Mohamed Ali, "Assessment of knowledge and attitude towards diarrheal disease in children under-five years in Shendi town," International Journal of ResearchGranthaalayah, vol. 4, no. 3, pp. 80-84, 2016.

[2] D. Dawit, E. Kumalo, Y. Yasin, and Y. Halala, "Assessment of knowledge, attitude \& practice of child care givers towards oral rehydration salt for diarrhea treatment in under 5 children in Wolaita Sodo town, SNNPR/2016," Journal of
Biology, Agriculture and Healthcare, vol. 7, no. 4, pp. 3-10, 2016.

[3] Y. Mumtaz, M. Zafar, and Z. Mumtaz, "Knowledge attitude and practices of mothers about diarrhea in children under 5 years in karachi hospital, Pakistan," Journal of Dow University of Health Sciences, vol. 8, no. 1, pp. 3-6, 2014.

[4] T. Dodicho, "Knowledge and practice of mothers/caregivers on home management of diarrhea in under five children in Mareka district, Southern Ethiopia," Journal of Health, Medicine and Nursing, vol. 27, no. 2422-8419, pp. 71-79, 2016.

[5] D. Amare, B. Dereje, B. Kassie et al., "Maternal knowledge and practice towards diarrhoea management in under five children in fenote Selam town, West Gojjam Zone, Amhara regional State, Northwest Ethiopia," Journal of Infectious Diseases and Therapy, vol. 2, no. 6, pp. 398-403, 2014.

[6] G. Gedamu, "Magnitude and associated factors of diarrhea among under five children in Farta wereda, North West Ethiopia," Insight Medical Publishing Group, vol. 25, no. 4, pp. 199-207, 2017.

[7] A. Hashi, A. Kumie, and J. Gasana, "Prevalence of diarrhoea and associated factors among under-five children in Jigjiga district, Somali region, Eastern Ethiopia," Open Journal of Preventive Medicine, vol. 6, no. 10, pp. 233-246, 2016.

[8] A. Abebaw, "Awoke worku \& TM: crossectional survey; assessment of diarrheal disease prevalence and associated factors among children under five in enemay district, Northwest Ethiopia," Global Journals Inc (USA), vol. 14, no. 3, pp. 17-21, 2014.

[9] M. Khalili, M. Mirshahi, A. Zarghami, M. Rajabnia, and F. Farahmand, "Maternal knowledge and practice regarding childhood diarrhea and diet in Zahedan, Iran," Health Scope, vol. 2, no. 1, pp. 20-23, 2013.

[10] Woreda water development office, Annual Report, 2017.

[11] WHO, Health for All Series, WHO, Geneva, Switzerland, 1984.

[12] Medical Dictionary, Free Online Dictionary, 2012.

[13] N. I. L. Debesay, A. Gebresilassie, H. Assefa, and D. Yemane, "Latrine utilization and associated factors in the rural communities of Gulomekada district, Tigray region, North Ethiopia," Community Medicine \& Health Education, vol. 5, no. 338, 2013.

[14] K. S. Ahmed, N. Mohamedkassm Siraj, H. Fitsumberhan et al., "Knowledge Attitude and practice (KAP) assessment of intestinal parasitic infection among school children in Asmara Eritrea," Health, vol. 9, no. 1, pp. 57-68, 2017.

[15] D. Getu, M. Gedefaw, and N. Abebe, "Childhood diarrheal diseases and associated factors in the rural community of Dejen district, Northwest Ethiopia," American Scientific Research Journal for Engineering, Technology, and Sciences (ASRJETS), vol. 51, no. 1, pp. 1-13, 2014.

[16] R. Paul and P. Kalidas, "A study on hand washing practices among mothers of under-five children in urban slums," Journal of Preventive Medicine and Holistic Health, vol. 3, no. 2, pp. 37-40, 2017.

[17] T. G. M. Chanie and K. Ketema, "Latrine utilization and associated factors in rural community of Aneded district, North West Ethiopia," Journal of Community Medicine \& Health Education, vol. 6, no. 5, pp. 2-8, 2016.

[18] E. O. Oloruntoba, T. B. Folarin, and A. I. Ayede, "Hygiene and sanitation risk factors of diarrhoeal disease among under-five children in Ibadan Nigeria," African Health Sciences, vol. 14, no. 4, pp. 1001-1011, 2014.

[19] H. Rumbo, B. Sanguanprasit, and S. Wichaikull, "Factors influencing preventive behaviors of mothers for diarrhea in 
children aged 1-5 years in Buol district, Indonesia," Sociology Study, vol. 6, no. 12, pp. 745-753, 2016.

[20] W. Godana and B. Mengiste, "Environmental factors associated with acute diarrhea among children under five years of age in Derashe district, Southern Ethiopia," Science Journal of Public Health, vol. 1, no. 3, pp. 119-124, 2013.

[21] A. A. Ghasemi, A. Talebian, N. M. Alavi, and G. A. Mousavi, "Knowledge of mothers in management of diarrhea in underfive children, in Kashan, Iran," Nursing and Midwifery Studies Health, vol. 1, no. 3, pp. 155-163, 2013.

[22] B. K. Desta, N. T. Assimamaw, and T. D. Ashenafi, "Knowledge, practice, and associated factors of home-based management of diarrhea among caregivers of children attending under-five clinic in Fagita Lekoma district, Awi Zone, Amhara regional State, Northwest Ethiopia, 2016," Nursing Research and Practice, vol. 2017, Article ID 8084548, 8 pages, 2017.

[23] A. Anteneh and A. Kumie, "Assessment of the impact of latrine utilization on diarrhoeal diseases in the rural community of Hulet Ejju Enessie Woreda, East Gojjam Zone, Amhara region," Ethiopian Journal of Health Development, vol. 24, no. 2, pp. 112-115, 2010.

[24] J. M. Olakunle, O. Valentine U, A. S. Kamaldeen, and A. S. Muhammad Buhari, "Assessment of mothers' knowledge of home management of childhood diarrhea in a nigerian setting," International Journal of Pharmaceutical Research and Bio-science (IJPRBS), vol. 1, no. 4, pp. 168-184, 2012. 


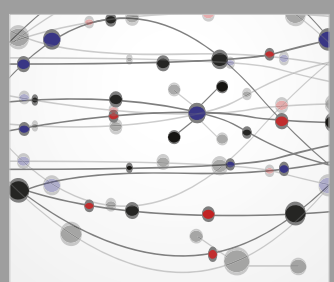

The Scientific World Journal
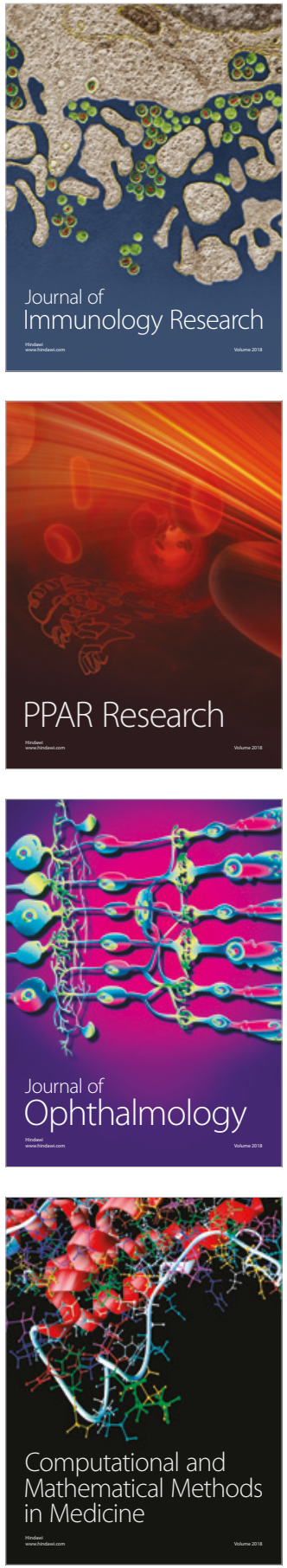

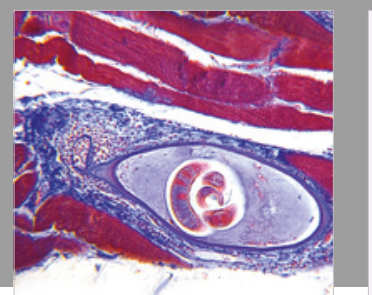

Gastroenterology Research and Practice

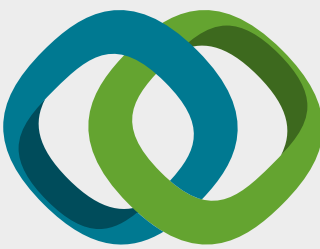

\section{Hindawi}

Submit your manuscripts at

www.hindawi.com
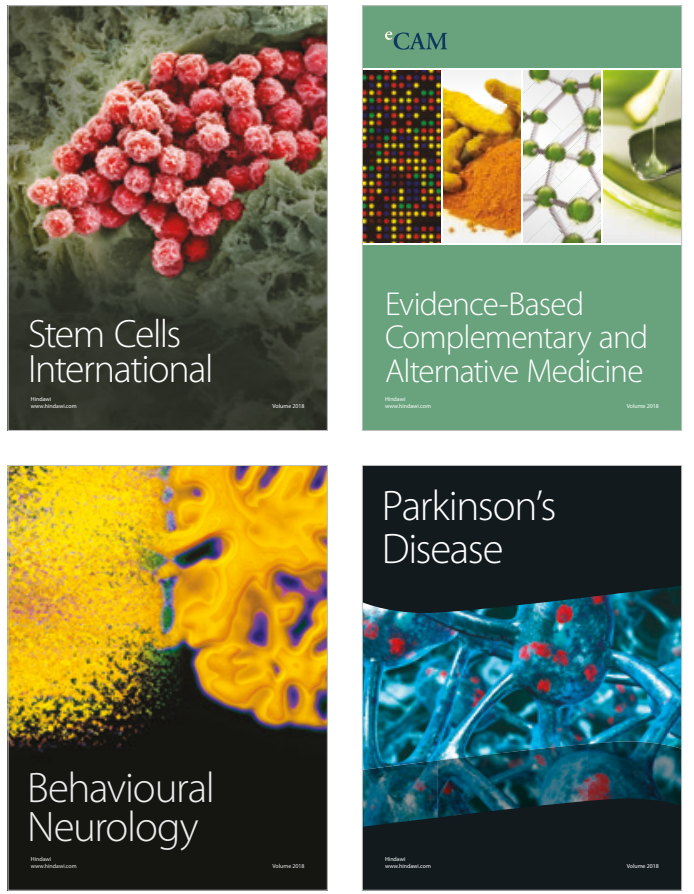

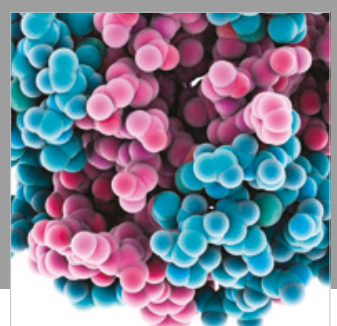

ournal of

Diabetes Research

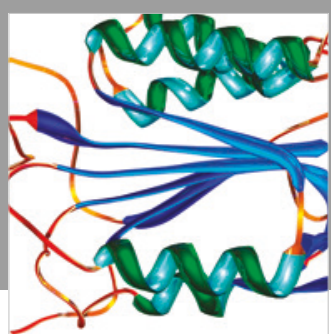

Disease Markers
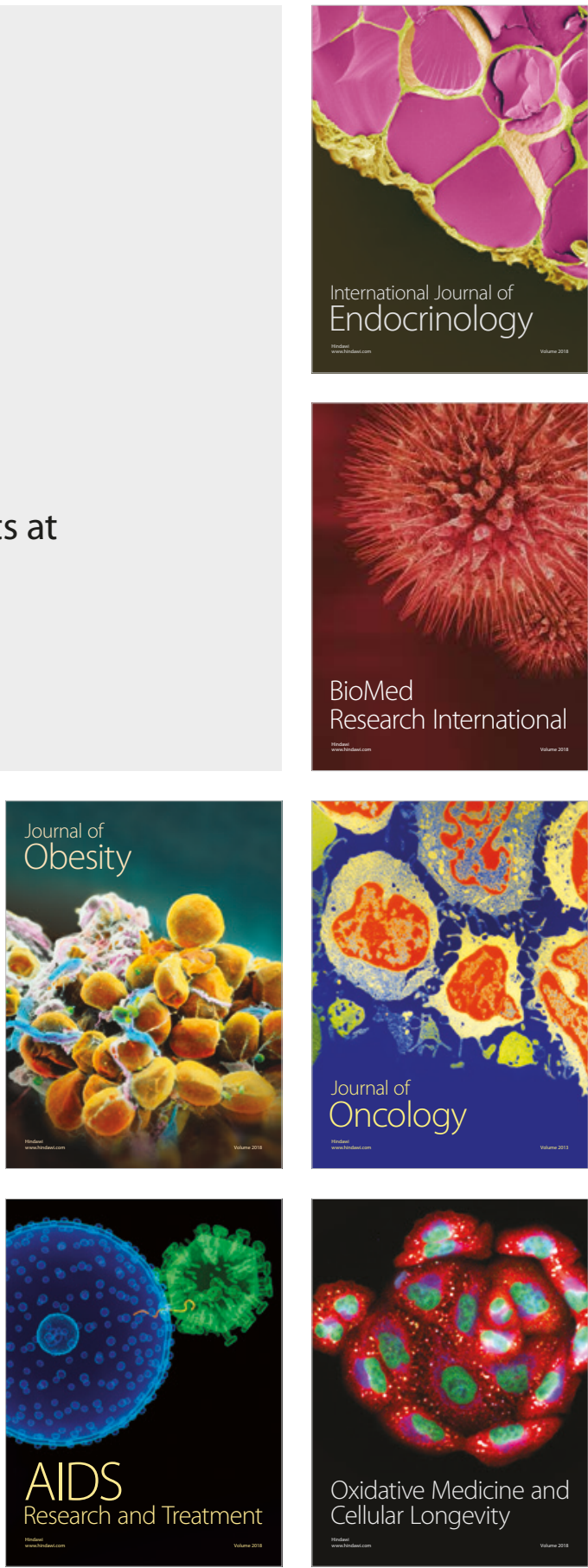